\title{
La institución de herederos en la sucesión ab-intestato: Transformaciones en la con- cepción de familia y herencia. Buenos Aires durante la primera mitad del Siglo XIX
}

\author{
María Selva Senor ${ }^{1}$
}

En el pasado como en el presente las comunidades humanas se han ordenado a partir de sus costumbres y tradiciones, es decir a través de su historia. Cada sociedad ha establecido los derechos y facultades de los sujetos. Los mismos fueron respaldados por alguna norma o institución, en otras palabras, se procedió a su ordenamiento como convivencia. Aquí encontramos dos sentidos del derecho, el primero como libertad y el segundo como ordenamiento.

Entonces, "Derecho" puede significar muchas cosas, pero fundamentalmente dos, una que tiene que ver con la facultad del sujeto -referente a la libertad- (derecho subjetivo) y otra relacionada con el orden de la sociedad (derecho objetivo). Debe quedar claro que el derecho no es exclusivamente ni una cosa ni la otra sino un orden que compagina a ambas. Este mecanismo presenta dificultades porque el movimiento los convierte en parte de un sistema complejo y delicado (Clavero 1992: 9-16). El presente trabajo, tiene por objeto observar ese mecanismo en funcionamiento; comprender la construcción de ese "ordenamiento" como parte de las necesidades de ciertos grupos, dando origen a una nueva concepción de familia y herencia durante la primera mitad del siglo XIX. Con esa finalidad, se consultarán las leyes castellanas referidas a sucesiones y las tesis de los aspirantes al título de "doctor en jurisprudencia" presentadas en la Universidad de Buenos Aires durante la primera mitad del siglo XIX. ${ }^{2}$

Debe señalarse que el rol de los intelectuales en la conformación del

1- Facultad de Ciencias Humanas, Instituto de Estudios Histórico-sociales (IEHS), U.N.C.P.B.A. Pinto 348, 7000 Tandil, Buenos Aires. Email: mariaselvasenor@yahoo.com.ar.

2- La Facultad de Derecho propiamente dicha, nace con la Universidad en 1822; su plan de estudios comprendía el Derecho Natural y de Gentes y el Derecho Civil. En 1826 se incorporó la cátedra de Derecho Público Eclesiástico. Pero además de esas disciplinas los estudiantes debían practicar en la Academia para ser abogados (Levene 1945). 
modelo familiar es vital para comprender la complejidad de la génesis de la familia rioplatense, sin descuidar el hecho de que el desarrollo cultural implica una interacción entre lo que George Mosse denomina el "talante general" (Mosse 1997), es decir, las reacciones ante las complicaciones cotidianas, las expectativas acerca de un futuro mejor y las ideas de los intelectuales que, en general, reflejan la actitud de un grupo social. De ese modo“... el intelectual puede ser un barómetro que expresa las ideas claramente y que define una determinada actitud, haciéndola inteligible en su propia época y para el futuro. Pero aunque el intelectual cree un fondo de ideas para la sociedad, la eficacia depende del análisis que él haya hecho de la actitud, las esperanzas y las necesidades de la época, o también de alguna futura" (Mosse 1997:15).

Durante mucho tiempo, inclusive una vez declarada la Independencia en el Río de la Plata, el Derecho Castellano mantuvo el "ordenamiento" de la sociedad $^{3}$. El derecho sucesorio común, a partir del cual se regulaba la transmisión de bienes, estaba integrado por el testamento y el orden de sucesión intestada 4 . Este derecho fue trasplantado al Nuevo Mundo, lo que supuso un cierto grado de complejidad debido a que la Corona y el Consejo, si bien contaban con detallados informes, tomaban decisiones sobre una realidad que les era ajena ${ }^{5}$, situación que colaboró en la conformación de un escena-

3- Los cuerpos legales sancionados y que podían aplicarse eran: la Ley de Toro (1505), Las Partidas (promulgadas entre 1256 y 1263), la Nueva Recopilación de Castilla (1567) y la Novísima Recopilación de las Leyes de España (1805 Clavero). Para comprender el funcionamiento de la legislación antes de que se dictaran los códigos y demás leyes orgánicas ver Cabral Texo 1933.

4- la regulación sucesoria de ciertos bienes se apartaba de este ordenamiento, tal es el caso de los bienes destinados a la fundación de mayorazgos, así definido por José María Alvarez, "El mayorazgo es una institución por la que se prohibe la enajenación de algunos bienes y se establece el orden de personas que han de suceder en su posesión" (Alvarez 1834:326).

5- En general, los trabajos sobre reproducción social en América Latina se han acercado al tema intentando establecer las consecuencias derivadas de la aplicación de las leyes castellanas sobre la herencia. A partir de las mismas, quedaba establecido que el capital adquirido durante el matrimonio pertenecía por partes iguales a los cónyuges; en consecuencia, al morir alguno de ellos, el que sobrevivía tenía derecho a la mitad de sus bienes. La parte correspondiente al difunto era distribuida en forma igualitaria entre sus hijos sin distinción de sexo. Ahora bien, esta distribución igualitaria podía modificarse a partir de mecanismos como la mejora (una tercera parte de los bienes era separada del resto para dar al hijo predilecto) y la quinta (la quinta parte podía legarse a otra persona o bien ser destinada a caridad). Esto propiciaba la disolución continua del patrimonio obligando a los jefes de distintas familias a recurrir a distintas estratagemas (Brading 1978; Socolow 1978). Estos trabajos fueron cuestionados con otras investigaciones que colocaron a los sujetos como agentes activos frente a los diferentes contextos normativos de cada sociedad, generando diversas estrategias frente a esas reglas en apariencia inmutables. Ejemplos de este tipo de aproximación pueden encontrarse en Moutoukias 1992:887. Otros trabajos que discuten la relación entre normas y prácticas pero para la campaña (Canedo 1998, Bjerg 1994, Zeberio 1995); también ver Bjerg, Otero, Zeberio 1996 y Bragoni 1999. 
rio repleto de contradicciones (Tau Anzoategui 1982).

En caso de que no se realizara testamento, las Partidas establecían por herederos a sus parientes; de acuerdo a los tres grados o líneas podían distinguirse: la de los descendientes legítimos, la de los ascendientes y la transversal o colateral. La primera línea excluía a las restantes. Pero, a falta de descendientes, la herencia era dividida entre los ascendientes. De no existir éstos, se convocaba a los hermanos. Y, si no se encontraban herederos de ningún grado los bienes ingresaban al fisco (Clavero 1992: 44- 47).

A partir del siglo XVIII, las ideas reformistas en Francia tendrán influencia en el pensamiento español, iniciándose en la segunda mitad del siglo una etapa de transformaciones impulsadas por el deseo de progreso, hecho que cobrará mayor significado durante el reinado de Carlos III (1759-1788). Sin embargo, en lo referente al sistema sucesorio, éste conservará matices del antiguo régimen ${ }^{6}$.

Las tesis de jurisprudencia permiten observar que, en la década del '30, comienzan a pronunciarse opiniones acerca de la necesidad de cambios referentes a la legislación; las mismas se harán más frecuentes en la década del '40. Las leyes españolas comienzan a ser fuertemente criticadas siendo caracterizadas por la mayoría de los tesistas con los adjetivos de "anticuadas" e "incompletas"; mencionándose además que las leyes castellanas no se adaptaban a las necesidades de la "sociedad argentina"7.

"Ardua tarea sin duda sería querer corregir una ley sancionada hace tantos años, tomada de la legislación más perfeccionada de la antigüedad: la legislación romana y adoptada constante y universalmente por una razón práctica, pero es indudable que una reforma meditada de nuestros códigos se impone porque el adelanto de nuestro siglo y la ilustración de los que guían los destinos de la humanidad lo reclaman imperiosamente." (Peralta1836$1837,10)$.

"...la ley Española antigua, la cual dictada por el Rey casi siempre para llenar necesidades de una monarquía o de sus colonias, no pueden en estos

6- El hecho de que la difusión de las ideas de la Ilustración descansara principalmente en algunos de los miembros de la Iglesia, imprimió a este proceso un sello particular, caracterizado por un acentuado eclecticismo. La escolástica continuaba siendo la base de los estudios y, en ocasiones, se incorporaban los aspectos menos relevantes de las teorías cartesianas o newtonianas (Chiaramonte 1994).

7- Oreste C. Cansanello observa un cambio en la relación habitante-Estado a partir de 1815. "De súbditos a ciudadanos. Los pobladores rurales bonaerenses entre el Antiguo Régimen y la modernidad" (Cansanello 1995). 
momentos ser la legislación que conviene y debe tener la Confederación Argentina..." (Conde 1848, foja 4).

"Estamos aun regidos en todo por leyes, que si tuvieron su razón en otras épocas, hoy están en abierta contradicción con el estado actual de la sociedad argentina y con las ideas filosóficas de los hombres más ilustrados del siglo." (García 1848, foja 2).

Pero, si bien es a partir de esa década cuando comienza a plantearse la necesidad de una reforma, ciertos indicios reflejados en las opiniones de los juristas anticipan una serie de cambios en las concepciones referentes a la herencia y a la familia misma. El ejemplo más claro puede verse en la institución de herederos, especialmente, cuando se trata de la sucesión abintestato ${ }^{8}$.

Las leyes castellanas establecían que, en caso de que la sucesión fuera ab-intestato, los bienes debían repartirse entre los herederos forzosos. En cuanto a cómo establecer quienes podían instituirse como tales, se privilegiaba como criterio el "amor"9. Así, en primer lugar, para heredar se encontraban los hijos, a falta de éstos los padres del difunto y, en caso de no poseer ni hijos ni padres, los parientes colaterales.

En el caso de los descendientes, existía una rigurosa clasificación. Se distinguían cuatro tipos: legítimos, legitimados, adoptivos e ilegítimos. Los hijos legítimos heredaban por igual, sin distinción de sexo ni edad. Los hijos de otros matrimonios así como los legitimados (por matrimonio), también heredaban del mismo modo. Entre quienes no podían instituirse como herederos se encontraban los hijos ilegítimos ${ }^{10}$. En el caso de los hijos naturales, si eran reconocidos y no existían descendientes legítimos, podían heredar las "dos duodécimas partes de sus bienes" (García 1848, foja 2); pero de existir descendientes legítimos, a los primeros sólo les correspondía una parte destinada a alimentos. Hubo jurisconsultos que criticaron estas leyes por dejar en último término al hijo natural, por "castigar" a un niño por la falta de sus

8- Se denomina sucesión ab-intestato a aquélla donde no se hizo testamento o donde el mismo no es acorde al Derecho (Alvarez 1834: 319).

9- El amor podía "bajar" o "subir"; dependía de si los bienes beneficiaban a los descendientes o, de no existir éstos, a los ascendientes. Y de no haber ni unos ni otros, podían instituirse como herederos los parientes colaterales (Alvarez 1834:319).

10- Sobre estos también existía una rigurosa clasificación. Las leyes distinguían entre "naturales" y "espurios"; con las categorías: "adulterinos o notos" (nacen de hombres casados y mujeres libres o ambos casados), "sacrílegos" (nacen de sacerdote y monja), "incestuosos" (los que nacen de parientes dentro del cuarto grado) y "manceres", o hijos de prostitutas (Alvarez 1834: 256). 
progenitores. Se argumentaba, que estas leyes fomentaban actitudes que iban en contra de los mismos deberes adjudicados al rol paterno ${ }^{11}$, demandando entonces leyes más "humanas" que los amparasen.

"Las leyes antiguas españolas dejaban en último término al hijo natural, quizás influenciadas por las costumbres y la tradición de condenar los amores ilícitos, como lo había hecho siempre la Iglesia, pero el espíritu de la civilización moderna ha corregido muchos abusos en que habían incurrido las costumbres primitivas, amparando hoy al inocente contra el desamparo de las legislaciones anticuadas..." (Herrera 1827:5).

Las leyes castellanas también establecían que los hijos espurios podían heredar bienes correspondientes a la madre, no así del padre. La razón era muy simple, no existían dudas acerca de la identidad de la madre (Alvarez 1834: 319). Se generaron muchas contradicciones, porque la mujer era considerada un ser más débil y de menor discernimiento que el hombre y, por lo tanto, fácilmente corruptible ${ }^{12}$. Este hecho fue duramente criticado e incluso se sugirió que el padre sin hijos instituyera a los hijos naturales como herederos universales en perjuicio de sus ascendientes; opinión basada en la injusticia implícita que significaba culpar a los hijos por los "pecados" de sus padres,

"... con respecto a la madre la ley no solamente obliga a esta sino también a sus ascendientes, siendo el fundamento la certeza de la maternidad... (Insiarte1847: 6)."13

11- Es notable como a partir de la década del ' 40 , los juristas van a dedicar cada vez más espacio a las características que involucran los distintos roles dentro de la familia: esposo-padre, esposa-madre. En las primeras décadas los deberes del hombre y de la mujer aparecen predeterminados por la naturaleza de su sexo; lo que significaba la debilidad de la mujer y la virilidad del hombre. Estos prejuicios se constituyen en los ejes vertebradores de toda una serie de derechos y obligaciones que van a desarrollarse con el paso del tiempo, “...sí señores, el hombre considerado en posición de padre, tiene que responder a la sociedad, al cielo mismo del resultado de su sagrada misión, así es que la conservación, educación y porvenir de la prole, no es un goce gratuito de que puede o no substraerse a su antojo, es una exigencia de su tranquilidad moral, reclamada imperiosamente por el grito de su conciencia..." (Obligado 1845: 5-6). Y podría continuarse con infinidad de ejemplos, “... el hijo desde que nace, esta amparado en la existencia de su padre, es de quien debe recibir sus alimentos, habitación, sus cuidados, vestido, educación y, en una palabra, todo lo que necesite y pueda serle útil para su subsistencia. Y esta obligación de los padres se prolonga hasta que el hijo se emancipe, y hasta que sea mayor de edad, o más si le es necesario..." (García 1849:7- 5).

12- Cuando los jurisconsultos utilizan la palabra "corromper" aclaran que este término incluye tanto a los actos donde se utiliza la violencia como a los voluntarios, puesto que la debilidad intrínseca al sexo femenino inhabilitaba a las mujeres para tomar cualquier decisión por sí mismas (Herrera 1827:2).

13- Esta opinión fue compartida por varios jurisconsultos, tal fue el caso de Basilio Salas, quien ya se había pronunciado a favor de una mayor consideración para con los hijos naturales por parte de la ley, "Sucesión de los hijos naturales" (Salas 1837). 
"El padre que no tiene hijos ni descendientes legítimos, puede instituir heredero universal de todos sus bienes a su hijo natural en perjuicio de sus ascendientes..." (Salas 1837).

"Aunque se diga que ellos no son legítimos, que ellos no son nacidos de la castidad conyugal sino de la incontinencia de su padre y de su madre, yo respondo en una palabra: ellos son inocentes, ellos son la obra de Dios también como los legítimos. Los hijos naturales son también como los legítimos una dependencia de su padre, una parte de sus ser..." (Herrera 1827, 5).

En cuanto al lugar que los hijos adoptivos debían ocupar, hubo ciertos desacuerdos entre los distintos cuerpos legales sancionados que podían aplicarse. Finalmente, la legislación del Fuero Real estableció que el adoptado no podía heredar a quien lo adopta ${ }^{14}$. Sobre este punto, para el período estudiado, se ha encontrado una sola tesis que argumenta a favor de esta disposición:

"No hay duda pues que el hijo adoptivo queda fuera de la sucesión si el padre tiene descendientes legítimos; y es necesario ir más allá; es necesario que también sean preferidos á tal hijo los ascendientes legítimos si los hay..." (Gorostiaga 1844:4).

A partir de las tesis puede observarse la importancia que cobra el tópico de la niñez y en especial los hijos naturales. ¿Cómo explicar el cambio?. Una respuesta posible podría encontrarse en la incapacidad por parte de las autoridades para controlar los altos índices de ilegitimidad así como el fenómeno de los niños abandonados ${ }^{15}$. En 1779, surge en Buenos Aires la "Casa de Niños Expósitos" (Barrán 1992). Algunas décadas mas tarde (1818), se crea en Montevideo la "Casa Cuna"16. El abandono de niños, así como los elevados porcentajes de ilegitimidad bien pudo inclinar a los intelectuales a ver la necesidad de otro tipo de sociedad, una sociedad más "disciplinada",

14- El tema de la adopción y del lugar de los hijos adoptivos en la sucesión constituyó una preocupación en distintas épocas y para distintas realidades. Jack Goody explica como la adopción fue prohibida por la Iglesia cristiana (en Europa hasta el siglo XX y en Estados Unidos hasta el siglo XIX). Según el autor, esto se explica a partir de que la Iglesia "se incorporó a la familia" y, en consecuencia, ella también era una heredera y rivalizaba como tal con cualquiera que pudiera interponerse (Goody 2001).

15- La ciudad de Buenos Aires vivió durante el siglo XVIII y principios del XIX un crecimiento demográfico sin precedentes en Hispanoamérica, en 1744 la ciudad contaba con 10.000 habitantes, pasa a 24.000 en 1778 y a 40.000 en 1810 . Esto puede explicar también la complejización de la situación social en la ciudad (Díaz y Moreno 1999).

16- José Pedro Barrán menciona que este fenómeno fue más intenso durante la primera mitad del siglo disminuyendo casi a la mitad a partir de la década del '60 (Barrán 1992: 76-78). 
pero para eso nadie debía ser exceptuado de responsabilidad. Es evidente que, para ciertos sectores, existía una necesidad de cambio, las leyes castellanas parecen sufrir un "desajuste" como "ordenamiento" dentro de esa sociedad $^{17}$.

También en cuanto a la institución de herederos, el lugar de la mujer va a conducir a controversias. Como puede notarse según lo expuesto anteriormente, las leyes castellanas no incluían a la mujer como heredera de su esposo (en el caso de sucesión ab-intestato). A la viuda le correspondía su parte de los bienes gananciales pero ningún porcentaje de los bienes de su cónyuge.

La importancia del traspaso se deduce, para los mismos tesistas, en que proveen la subsistencia de los supervivientes para que continúen disfrutando de los bienes del difunto. El orden de los herederos, debía determinarse teniendo en cuenta el "mayor afecto", entonces, por qué la mujer no era mencionada como heredera en el orden de sucesión ab intestato. Varios aspirantes consideraron contradictorio el hecho de que la misma ley olvidara por completo a la mujer; corriéndose el peligro de que, de no existir herederos -descendientes, ascendientes ni colaterales-, los bienes quedaran para el fisco excluyendo así a la misma viuda:

“...pero estas leyes fundadas en el mayor afecto, olvidan por completo a la muger, al ser de tan grandes afecciones para el compañero de su vida, prefieren a ella a los colaterales y después al fisco. Así lo disponían las leyes romanas, (...) que como todas las leyes debían haber sido dictadas para oprimir a la muger, (estas) fueron el fundamento de las leyes españolas. Ellas tampoco quieren admitir que el afecto del esposo es mayor para la muger que para los parientes colaterales". (Peralta 1836-1837:7-8).

"...Desde que se liga la muger con el indisoluble vínculo del matrimonio entra a ser partícipe con su esposo de la fortuna que posee, con la

17- José Mateo explora exhaustivamente la significación de la ilegitimidad y el concubinato en la campaña, concretamente en Lobos, y explica como para la campaña no debe establecerse una relación directa entre la ilegitimidad de los nacimientos y la estabilidad de las uniones. Para el caso que analiza, el autor concluye que las parejas unidas en concubinato y los padres de bastardos no son menos estables que aquellos unidos por matrimonio (Mateo 1996). El contraste entre ciudad y campaña es muy marcado con respecto a estos temas, una simple evidencia puede encontrarse en el mismo cuadro que el autor realiza en la página 17 "Tasas de ilegitimidad en América y Europa", si se observan los porcentajes de ilegitimidad para la ciudad de Buenos Aires (17\%, 1856), para Tandil $(35 \%, 1860)$ y Lobos (47,2\%, 1840-1846), vemos que para la campaña evidentemente el porcentaje de ilegitimidad es más alto, y podría estar reflejando el efecto de un mayor "control social" en la ciudad. 
esperanza de que si la muerte llegára á privarla de un hombre que la proteja y sostenga, no la privará al mismo tiempo de sus bienes para proveer a su subsistencia, ó para poder mantenerse con honor y comodidad en el rango que en la sociedad ocupare..." (Huergo 1843-1844: 6).

"...más qué significa esta ley señores? (se refiere a la Recopilación). No parece sino que el legislador lo que pretendió fue impedir que la esposa pueda heredar a su marido, amparando a los parientes colaterales, pero sin hacer distinción de grados, de modo que la línea de los colaterales se estendía indefinidamente y cuando concluyen los bienes iban a parar a poder de las arcas reales"18 (García 1848, 8).

Esta preocupación por parte de los juristas acerca del lugar de la mujer, pone en evidencia una consideración diferente, principalmente en su rol de madre y esposa. Se ha señalado en otro trabajo (Senor 2001), que durante las primeras décadas del siglo, los deberes del hombre y de la mujer aparecen predeterminados por la naturaleza de su sexo. Es decir, la debilidad de la mujer y la virilidad del hombre constituyen los ejes vertebradores de toda una serie de derechos y obligaciones que van a desarrollarse a lo largo del siglo. A partir de la década del '40, la mujer comienza a ser destacada como "compañera de la vida", como apoyo de su marido e inclusive se admite su capacidad para "educar" a los niños durante los primeros años ${ }^{19}$. Este reconocimiento requiere de su contraparte material. En otras palabras, el afecto y las atenciones que una mujer dispensaba a su esposo debían ser reconocidos tanto en términos materiales -a partir de la participación en la herenciacomo legales, esto último implicaba un cambio en la legislación vigente.

\section{Consideraciones finales}

La búsqueda de seguridad por parte de los miembros de la sociedad occidental parece haber constituido una constante en un mundo de naturale-

18- Las citas podrían continuarse, inclusive hubo tesistas que llegaron más lejos al proponer que la mujer debía estar antes que los ascendientes inclusive, a falta de hijos legítimos, “...si la muger es el punto de apoyo del otro sexo y con esa dulzura y amabilidad que le son propias aumenta la felicidad del esposo, neutraliza o mitiga el desconsuelo inherente a sus privaciones y padecimientos, ¿qué cosa más natural que muerto este y dejando bienes, pertenezcan a su muger en defecto de hijos legítimos antes que a los ascendientes y con mucha mayor razón que a los colaterales?" (Seguí 1849,1850:5).

19- Según un trabajo de Silvia Mallo, a partir de publicaciones del siglo XVIII, se advierte a los hombres del peligro de dejar la educación de sus hijos en manos de sus esposas. Se ve a las mismas, por la debilidad intrínseca a su sexo, inclinadas hacia la superstición (Mallo 1990: 120).

.80 . 
za equívoca. En diversos momentos, se gestaron respuestas que se tradujeron en ideas defendidas por diversos movimientos como por ejemplo, el romanticismo y el liberalismo, que intentaron dar solución a una industrialización que cambiaba a un ritmo acelerado el rostro de la sociedad, amenazando con el exterminio de las pautas y costumbres tradicionales. Frente a esta marea inevitable, comenzó a forjarse en Europa la noción de "respetabilidad" de carácter inmutable que recién logró imponer sus normas de conducta y actitudes morales entre fines del siglo XVIII y la primera mitad del XIX.

En este contexto, la familia se transformó en una pieza fundamental, puesto que se constituyó en la salvaguarda de la respetabilidad. Cada miembro de la misma deberá cumplir un rol específico, colaborando en la conservación de los nuevos valores; el matrimonio, si bien continúa en muchos sectores significando un intercambio económico, deja de ser considerado como tal, y el afecto entre marido y mujer se constituye en una variable fundamental. De este modo, los pilares de la respetabilidad -virilidad, castidad, autocontrol y moderación- echan raíces en la institución familiar.

Si bien es cierto que las sociedades latinoamericanas también se constituyeron en objeto y sujeto de ese "proceso de civilización" (Elías 1993), marcadas diferencias las separan del caso europeo. En los "países nuevos" -como se les Ilamaba a los semicoloniales de América Latina en el siglo XIXconvivían sistemas económicos y culturales de tiempos diferentes. Además el proceso inmigratorio y la relación con los países imperialistas conformaron realidades donde los cambios lentos fueron casi inexistentes. De ese modo, procesos culturales que en Europa duraron siglos y fueron casi imperceptibles -la "larga duración" de Braudel-, en estos países perduraron apenas algunos decenios (Barrán 1992:14). La región rioplatense tuvo que convivir con dos "sensibilidades" (Barrán 1992, 221) ${ }^{20}$ al mismo tiempo; las que José Pedro Barrán identificó como "bárbara" -vinculada al mundo precapitalistay la "civilizada", con rasgos capitalistas y conductas burguesas.

A partir de las tesis de jurisprudencia, se desprende que las leyes casteIlanas -al menos aquellas referidas a la herencia-, se revelan anticuadas frente a las necesidades de la temprana Argentina. Se trata de una característica que estos intelectuales van a señalar cada vez con mayor frecuencia a partir de la

20- Cabe aclarar que si bien ambas sensibilidades conviven, durante la primera mitad del siglo prima la sensibilidad que Barrán identifica como "bárbara" y que la "disciplinada" recién se impondrá a partir de 1860 . 
década del '40. En realidad, no se trata sólo de las leyes; ciertas costumbres de la sociedad misma se presentan como resabios enemigos del "progreso". Baste señalar como ejemplos el hecho de "castigar" a los hijos naturales por la "incontinencia" de los padres y dejar que una mujer, ser "naturalmente" mas débil, cargue sola el fruto de la ilegitimidad. Si se pretendía una sociedad más "civilizada", había que comprometer a todos y a cada uno de los miembros de la misma, pero para eso serán necesarias una serie de reglas y normas que colaboren en el "disciplinamiento" de cada uno de ellos.

Cabe preguntarse ¿hasta qué punto son representativas estas ideas esbozadas por un grupo de futuros juristas?. Una de las posibilidades para responder, es acudir a los cientos de casos de índole privada que buscaban solución en los tribunales ${ }^{21}$. Entre los juicios criminales que tuvieron lugar a principios del siglo XIX, los problemas giraron en torno a: patrimonio $(17,5 \%)$, calumnia e injurias $(40 \%)$, malos tratos (20\%; incluían excesos, abuso físico y violencia), adulterios (12,5\%) y violaciones (10\%) (Cicerchia 1990). Las decisiones de la justicia colaboraban entonces en cuanto a una noción de la "moral" a seguir. Por otra parte, los tesistas que obtuvieron sus títulos, citados en este trabajo, pasaron a constituir, en su mayoría, el aparato político y judicial $^{22}$. Y además, las ideas que aquí esbozan se imponen hacia fines de siglo. Esto no quiere decir que los individuos entren en forma automática a respetar una serie de reglas. El nuevo ordenamiento ira construyéndose a partir del juego dialéctico entre la sociedad y el Estado.

21- Este juego entre familia, justicia y Estado ha sido ampliamente desarrollado para el caso europeo por Arlette Farge y Michel Foucault, quienes a partir del análisis de las lettres de cachet, documentos dirigidos al Rey para solicitar la reclusión de algún miembro de la familia, descubren que los sectores populares, principalmente, eran quienes recurrían a estos medios para evitar los "disturbios" en el barrio. De este modo, los autores desmitifican la tesis que sostenía que esta reclusión era producto de la cólera o del capricho del rey (Farge y Foucault 1982).

22- Algunos ejemplos, García, Juan Agustín:Nació en Buenos Aires en 1831. Se graduó en la Universidad de Buenos Aires de doctor en Jurisprudencia en 1849. Fue secretario del General Paz y más tarde diputado a la legislatura desde 1857. Hizo periodismo. Posteriormente fue relator del superior Tribunal de Justicia, juez de primera instancia en lo civil hasta 1862, año en que entró a formar parte del Congreso como diputado de la Provincia hasta 1866 . Hasta 1873 vicepresidente del Partido Nacional, ejerció la presidencia del Club del Progreso en 1874. Participó en los acontecimientos revolucionarios entre 1874-78, motivo por el cuel fue desterrado a Montevideo. En 1885 vuelve a ser diputado por la provincia de Buenos Aires. En 1885 fue director del Banco Nación y luego primer presidente del Banco Hipotecario Nacional. Posteriormente fue Ministro de Hacienda de la Nación. Fue miembro de la Comisión redactora del proyecto de Codigo Penal, miembro de la Cámara en lo criminal y comercial (Cutolo, 1968). Gorostiaga, José Benjamín: Nació en Santiago del Estero en 1823. Emigra con su familia a Buenos Aires donde realiza sus estudios de jurisprudencia. Practicó la abogacía, desempeñó el cargo 


\title{
Resumen
}

Dentro del "Derecho" pueden diferenciarse el derecho subjetivo (relacionado con la facultad del sujeto -referente a la libertad-) y el derecho objetivo ( relacionado con el orden de la sociedad). El derecho, no es exclusivamente ni una cosa ni la otra sino un orden que compagina a ambas. Este mecanismo presenta dificultades porque el movimiento los convierte en parte de un sistema complejo y delicado. El presente trabajo tiene por objeto observar ese mecanismo en funcionamiento; comprender la construcción de ese "ordenamiento" como parte de las necesidades de ciertos grupos y ver como se plasman dando origen a una nueva concepción de familia y herencia durante la primera mitad del siglo XIX.

\section{Palabras claves}

derecho - familia - herencia - herederos.

\begin{abstract}
The establishment of heirs in the succession ab-intestato: transformations in the conception of family and inheritance. Buenos Aires during the first half of XIX century
\end{abstract}

Within the Law, it is possible make a difference between subjective rights (individual's faculty) and objective rights (society's order). The Law is not exclusively one or the other; but rather an order which

de celador fiscal. El gobernador Vicente López y Planes lo nombró ministro de Hacienda (1852). En ese mismo momento fue electo constituyente. Defendió el proyecto de constitución siendo su principal redactor. Después de Pavón fue elegido diputado nacional por Santiago del Estero. En 1890 actuó con los revolucionarios. Muere en 1891(Cutolo, 1968). Herrera, Mauricio: Nació en Catamarca en 1787. Era federal. La legislatura catamarqueña lo designó gobernador de la provincia en 1835. Enfrentó levantamientos y fue vencido por el gobernador de Tucumán siendo desterrado a Buenos Aires. Huergo, Delfín Bonifacio: Constituyente y funcionario, nació en Salta el 14 de diciembre de 1824; murió en Buenos Aires el 17 de diciembre de 1886. Se graduó en leyes en 1846 y en seguida se alistó en las filas del ejército libertador de Urquiza; asistió a la Batalla de Caseros y fue electo al año siguiente constituyente por San Luis al Congreso de Santa Fe; sostuvo que no había llegado el momento todavía de sancionar la Constitución a causa del estado del país. Formó parte del gobierno de Paraná y medió con su influencia a favor de la celebración de la paz entre la Confederación y la provincia de Buenos Aires. En 1859 fue nombrado ministro argentino en Alemania; posteriormente fue subsecretario del ministro de relaciones exteriores; representó al país en Bélgica, cargo que hubo de abandonar por enfermedad, y al que volvió en 1883 (Cutolo 1968). 
connects both parts. This mechanism shows difficulties because the movement makes them part of a complex and delicate system. This paper attempts to observe this mechanism working; to understand the construction of this order as part of the new needs of certain groups and see how they take shape giving birth to a new conception of family and inheritance during the first half of XIX century.

\section{Key words}

law - family - inheritance - heirs.

\section{Fuentes documentales ${ }^{23}$}

*CONDE, Nicolás(1848), "Derechos hereditarios de los sobrinos nietos", Colección Candioti, Buenos Aires, Tomo 7.

*GARCIA, Juan Agustín (1848), "Sobre los derechos hereditarios de la mujer casada", Colección Candioti, Buenos Aires, Tomo 7.

*HERRERA, Mauricio (1827), "Sobre que no valga una donación hecha a unos hijos naturales teniendo legítimos", Colección Candioti, Buenos Aires, Tomo 1. *HUERGO, Delfin B. (1843-1844), "Derechos de la muger a la sucesión de los bienes de su esposo intestado con preferencia a los parientes colaterales", Colección Candioti, Buenos Aires, Tomo 5.

*GOROSTIAGA, José (1844), "Los ascendiente legítimos ocupan en la escala de las sucesiones ex-testamento y ab-intestato un lugar preferente a los hijos adoptivos", Colección Candioti, Buenos Aires, Tomo 5.

*INSIARTE, Adolfo (1847), "Sucesiones", Colección Candioti, Buenos Aires, Tomo 6.

*PERALTA, Vicente (1836-1837), "Derechos hereditarios de la mujer en la sucesión ab intestato del marido", Colección Candioti, Buenos Aires, Tomo 3.

*OBLIGADO, Pastor (1845), "Los hijos naturales y los espurios que habilitados para suceder a la madre, siempre que sean reconocidos por sus padres, deben ser preferidos a los ascendientes legítimos en las herencias intestadas", Colección Candioti, Buenos Aires, Tomo 6.

*SALAS, Basilio (1837), "Sucesión de los hijos naturales", Colección Candioti, Buenos Aires, Tomo 3.

*SEGUI, Juan Francisco (1849-1850), "La sucesión ab-intestato excluyendo a la muger legítima”, Colección Candioti, Buenos Aires, Tomo 7.

23- Se trata de Tesis de jurisprudencia. 


\section{Bibliografía}

*ALVAREZ, José María (1834), Instituciones del derecho Real de España, Buenos Aires, Imprenta del Estado.

*BJERG, Mónica (1994), Dinamarca bajo la cruz del sur. Los asentamientos de daneses del centro-sur de la provincia de Buenos Aires, 1850-1930, Tesis doctoral, UBA.

*BJERG, Mónica, Hernán OTERO y Blanca ZEBERIO (1996), "De hijos excluido a padres igualitarios. Prácticas de herencia de vascos y daneses en las tierras nuevas del sur bonaerense, 1870-1930”, en: BJERG, Mónica, OTERO Hernán y ZEBERIO, Blanca, Reproducción social y sistemas de herencia en una perspectiva comparada: Europa y los paises nuevos (siglo XVIII al XX,) Tandil, IEHS, pp. 191-215.

*BARRAN, José Pedro (1992), Historia de la sensibilidad en el Uruguay. La cultura "bárbara", Uruguay, Ediciones de la Banda Oriental.

*BOURDIEU, Pierre (1972), "Normes et déviances. Les stratégies matrimoniales dans le systéme de reproduction", en: Annales ESC. nro. 27, 4-5, pp. 1105-1127.

*BRADING, David (1978), Mineros y comerciantes en el México borbónico (1763-1810), México, Grijalbo, 1978.

*BRAGONI, Beatriz (1999), Los hijos de la revolución. Familia, negocios y poder en Mendoza en el siglo XIX, Buenos Aires, Taurus.

*CANEDO, Mariana (1998), "Tierra sin gente y gente con tierra. La dinámica del acceso y de la transferencia de la tierra en una zona de colonización temprana de la campaña de Buenos Aires (Los Arroyos, 1600-1850)", en: ZEBERIO, Blanca, BJERG, Mónica, OTERO, Hernán (comps.) Reproducción social y sistemas de herencia en una perspectiva comparada. Europa y los países nuevos (siglos XVIII al XX), Tandil, Instituto de Estudios Histórico-sociales, UNCPBA, pp. 83-119.

*CANSANELLO, Oreste C. (1995), "De súbditos a ciudadanos. Los pobladores rurales bonaerenses entre el Antiguo Régimen y la modernidad", en: Boletín del Instituto de Historia Argentina y Americana 'Dr. Emilio Ravignani', Buenos Aires, tercera serie, núm. 11, pp. 113-139.

*CABRAL TEXO, Jorge (1933), Prelación de los cuerpos legales en la Historia del Derecho Argentino, Buenos Aires, Imprenta de la Universidad.

*CERUTTI, Simona (1997), "Normes et pratiques, ou de la légitimé de leur opposition", en: Les formes de l'expérience. Une autre histoire sociale., Francia, Editorial Albin Michel. 
*CHIARAMONTE, José Carlos (1994), La crítica ilustrada de la realidad. Economía y sociedad en el pensamiento argentino e iberoamericano del siglo XVIII, Buenos Aires, CEAL.

*CICERCHIA, Ricardo (1990), "Vida familiar y prácticas conyugales. Clases populares en una ciudad colonial, Buenos aires, 1800-1810”, en: Boletín del Instituto de historia Argentina y Americana "Dr. Emilio Ravignani”, Buenos Aires, tercera serie, número 2, 1er semestre, pp. 91-109.

*CICERCHIA, Ricardo (1998), Historia de la vida privada en la Argentina, Buenos Aires, Troquel.

*CLAVERO, Bartolomé (1992), Institución histórica del Derecho, Madrid, Marcial Pons.

*CUTOLO, Vicente Osvaldo (1968), Nuevo Diccionario Biográfico Argentino, Buenos Aires, Editorial Elche.

*DIAZ, Marisa y José Luis MORENO (1999), "Unidades domésticas, familias, mujeres y trabajo en Buenos Aires a mediados del siglo XVIII", en: Entrepasados, vol.8, n 16, pp. 25-42.

*ELIAS, Norbert (1993), El proceso de la civilización, Buenos Aires, Fondo de Cultura Económica, (1ra. impresión en alemán, 1977 tomo 1 y 1979, tomo 2).

*FARGE, Arlette y Michel FOUCAULT(1982), Le désordre des familles, Paris, Gallimard.

*GOODY, Jack (2001), La familia europea, Barcelona, Crítica.

*LEVENE, Ricardo (1945), Historia del Derecho Argentino, Buenos Aires, Editorial G. Kraft.

*MALLO, Silvia (1990), “La mujer rioplatense a fines del siglo XVIII. Ideales y realidad", en: Anuario IEHS V, pp.117-132.

*MATEO, José (1996), "Bastardos y concubinas. La ilegitimidad conyugal y filial en la frontera pampeana bonaerense (Lobos, 1810-1869), en: Boletín del Instituto de Historia Argentina y Americana 'Dr. Emilio Ravignani', nº 13, 3ra serie, 1er semestre, pp. 7-57.

*MOSSE, George (1997), La cultura europea del siglo XIX, Barcelona, Ariel. *MOUTOUKIAS, Zacarías (1992), "Réseaux personnels et autorité coloniale: les négociants de Buenos Aires au XVIIIe siècle”, en: Annales, ESC, n 4-5, pp. 889-915.

*SENOR, María Selva (2001), “La conformación de la 'familia modelo'. El papel de los intelectuales durante la primera mitad del siglo XIX". Jornadas Interescuelas-Departamentos de Historia, Salta, 2001 (inédito).

*SOCOLOW, Susan (1978), Los mercaderes del Buenos Aires virreinal: fami- 
lia y comercio, Buenos Aires, Ediciones De la Flor.

*TAU ANZOATEGUI, Víctor (1982), Esquema histórico del derecho sucesorio, Buenos Aires, Editorial Macchi.

Recibido: 20/06/03

Aceptado: 21/08/04 